\title{
AVALIAÇÃO E INTERVENÇÃO DA DISORTOGRAFIA BASEADA NA SEMIOLOGIA DOS ERROS: REVISÃO DA LITERATURA
}

\author{
Evaluation and intervention of dysortographia \\ based on error semiology: literature review
}

\begin{abstract}
Amparo Ygual Fernández ${ }^{(1)}$, José Francisco Cervera Mérida ${ }^{(2)}$, Vera Lúcia Orlandi Cunha ${ }^{(3)}$, Andrea Oliveira Batista ${ }^{(4)}$, Simone Aparecida Capellini ${ }^{(5)}$
\end{abstract}

\section{RESUMO}

Tema: avaliação e intervenção na disortografia. Objetivo: descrever e discutir os achados encontrados na literatura sobre a disortografia segundo a sua definição, etiologia, classificação da semiologia dos erros, quadro clínico, avaliação e intervenção. Conclusão: a avaliação e a intervenção fonoaudiológica com a disortografia devem estar baseadas na classificação semiológica dos erros, pois desta forma, pode-se compreender cada tipo de erro e os fatores cognitivos ou linguísticos implicados. Isso se associa às orientações aos pais e professores de como enfocar o trabalho com a ortografia, seja em casa ou na escola sem gerar angústia e ansiedade na criança.

DESCRITORES: Avaliação; Reabilitação; Escrita Manual; Transtornos de Aprendizagem

(1) Logopeda e Piscóloga; Docente do Departamento de Psicologia Evolutiva, do Departamento de Educação e do Programa de Pós-Graduação em Dificuldades de Aprendizagem da Universidade de Valencia, Valencia, Espanha; e do Programa de Pós-Graduação de Logopedia da Universidade Católica de Valencia San Vicente Mártir, Valencia, Espanha; Doutora em Psicologia pela Faculdade de Psicologia da Universidade de Valencia, Espanha.

(2) Logopeda e Biólogo; Docente da diplomatura de Logopedia e Diretor de Mestrado Oficial "Intervenção Logopédica Especializada" na Universidade Católica de Valencia San Vicente Mártir, Valencia, Espanha; Mestre em Logopedia pela Universidade Autônoma de Barcelona, Espanha.

(3) Fonoaudióloga; Mestre e Doutoranda do Programa de Pós-Graduação em Educação da Faculdade de Filosofia e Ciências da Universidade Estadual Paulista. Bolsista CAPES.

(4) Fonoaudióloga clínica; Centro de Estudos e Reabilitação Humana - CERH, Londrina, PR, Brasil. Mestranda do Programa de Pós-Graduação em Educação da Faculdade de Filosofia e Ciências da Universidade Estadual Paulista.

(5) Fonoaudióloga; Docente do Departamento de Fonoaudiologia e do Programa de Pós-Graduação em Educação da Faculdade de Filosofia e Ciências da Universidade Estadual Paulista, FFC/UNESP, Marília, SP, Brasil; Doutora em Ciências Médicas pela Faculdade de Ciências Médicas da Universidade Estadual de Campinas.

Conflito de interesses: inexistente

\section{INTRODUÇÃO}

A criança ao ingressar na escola possui o domínio do sistema linguístico em sua modalidade oral e, portanto, encontra-se com suas habilidades linguístico-cognitivas adequadas para a aprendizagem da leitura e escrita. No entanto, apesar de ter domínio dessas habilidades na oralidade, a criança não tem noção de quais aspectos fonológicos relacionados com a linguagem oral são necessários para ler e escrever. Assim, quando entra em contato com a escrita, ela se depara com um novo sistema, em que precisa utilizar novas regras e voltar sua atenção para elementos até então imperceptíveis ${ }^{1}$.

Para isso, é necessário que a criança desenvolva suas capacidades metalinguísticas, ou seja, que ela passe a refletir sobre sua linguagem. Essa reflexão envolve a atenção aos aspectos da linguagem nos níveis fonológico, morfológico e sintático e não apenas ao seu conteúdo, no nível semântico. A capacidade metalinguística, em seu nível fonológico, faz com que a criança reflita sobre o sistema sonoro da língua, tendo consciência de frases, palavras, sílabas e fonemas como unidades menores ${ }^{2,3}$. 
A correlação entre a consciência fonológica e o desempenho em atividades de leitura e escrita foi abordada em diversos estudos, sendo motivo de controvérsias. Três diferentes posições são apontadas pelos pesquisadores, conforme descrito a seguir ${ }^{4,5}$.

Em uma primeira posição, estão aqueles que acreditam que a consciência fonológica (enquanto habilidade para detectar rima e aliteração) ocorre a partir do progresso na aquisição da leitura e escrita, devido ao uso de analogias, da habilidade de perceber que duas palavras rimam, tornando a criança sensível às semelhanças ortográficas no final dessas palavras e, assim, possibilitar o estabelecimento de conexões entre padrões ortográficos e sons no final das palavras.

Para esses autores, a consciência fonológica é considerada a chave para o desenvolvimento da alfabetização. Esse papel central da consciência fonológica sobre a aprendizagem da leitura e da escrita é atestado, segundo os autores, por numerosos trabalhos de pesquisa, com seus resultados demonstrando que o desempenho de crianças préescolares em determinadas tarefas de consciência fonológica relaciona-se com o sucesso na aquisição da leitura e da escrita ${ }^{6,7}$.

Na segunda posição, encontram-se aqueles que defendem que a instrução formal do sistema alfabético é o fator ou causa primordial para o desenvolvimento da consciência fonológica. A capacidade de fazer analogias no final das palavras pressupõe habilidade de decodificação letra-som, sendo que a capacidade de detectar fonemas em uma palavra é influenciada pelo conhecimento ortográfico ${ }^{1,8}$.

Já em uma terceira posição, destacam-se os autores que veem uma relação de reciprocidade entre a consciência fonológica e a aquisição da leitura e escrita. Esses autores explicam que os estágios iniciais da consciência fonológica contribuem para o estabelecimento dos estágios iniciais do processo de leitura, e estes, por sua vez, contribuem para o desenvolvimento de habilidades fonológicas mais complexas. Dessa forma, enquanto a consciência de alguns segmentos sonoros (suprafonêmicos) parece desenvolver-se naturalmente, a consciência fonêmica parece exigir experiência específica em atividades que possibilitam a identificação da correspondência entre os elementos fonêmicos da fala e os elementos grafêmicos da escrita. Este processo de associação grafema-fonema exige um desenvolvimento de análise e síntese de fonemas $^{\text {9-11. }}$.

Para se chegar à descoberta do fonema, é necessário adquirir e desenvolver a consciência fonológica, que se trata da competência metalinguística que possibilita o acesso consciente ao nível fonológico da fala e à manipulação cognitiva das representações neste nível. O contato com a linguagem escrita possibilita 0 desenvolvimento desta capacidade, sendo que este desenvolvimento auxilia nos níveis mais avançados de leitura e escrita ${ }^{9,10}$.

Apesar desta controvérsia, todos os autores citados são unânimes em concordar que as tentativas de leitura e escrita por parte de leitores e escritores iniciantes têm, em geral, mais sucesso se estes compreenderem o que é o princípio alfabético, pois, dessa forma, eles poderão fazer uso de maneira mais eficaz da informação obtida pela decodificação letra-som, habilidade que apresenta um acometimento importante no escolar com problemas de aprendizagem ${ }^{12}$. Esse acometimento geralmente está relacionado com a dificuldade no mecanismo de conversão letra-som, ocasionando os chamados erros de natureza fonológica e ortográfica, características da disortografia.

O objetivo desta revisão de literatura foi descrever a disortografia segundo a sua definição, etiologia, classificação e quadro clínico. Além disso, propõe-se uma breve revisão da literatura internacional e nacional sobre os estudos sobre avaliação e intervenção na disortografia.

\section{MÉTODOS}

A revisão da literatura foi realizada a partir de livros, monografias, teses, dissertações e artigos, em sua maioria, publicados pelo LILACS, PUBMED, SCIELO e MEDLINE. Foram utilizados os estudos mais relevantes relacionados à definição, etiologia, classificação e quadro clínico da disortografia, bem como a avaliação e intervenção com a disortografia. Não foi estabelecido um período para o levantamento bibliográfico uma vez que esta temática ainda é escassa tanto na literatura nacional como internacional. Os descritores utilizados em português para o levantamento bibliográfico fora: avaliação, intervenção, escrita manual e transtornos de aprendizagem em inglês: evaluation, intervention, handwriting, writing e learning disorders; e em espanhol: escritura manual, evaluación, intervención e trastornos del aprendizaje.

\section{REVISÃO DA LITERATURA}

\section{Disortografia: definição, etiologia e quadro clínico}

O Transtorno Específico da Escrita, também conhecido como Disortografia, é uma alteração na planificação da linguagem escrita, que causa transtornos na aprendizagem da ortografia, gramática e redação, apesar de o potencial intelectual e a escolaridade do indivíduo estarem adequados para a idade ${ }^{13}$. 
Disortografia, portanto, compreende um padrão de escrita que foge às regras ortográficas estabelecidas convencionalmente, que regem determinada língua. Os escolares que começam a alfabetização com dificuldade para a aprendizagem da ortografia provavelmente chegarão ao final do ensino fundamental com dificuldades ortográficas ${ }^{14,15}$. Isso provocaria um impacto negativo para o desempenho acadêmico geral, pois ler e escrever, enquanto processos de decodificação ou grafofonêmico e de codificação ou fonografêmico, ou seja, o reconhecimento das letras e os valores atribuídos aos grafemas no reconhecimento das palavras e a possibilidade de codificá-los, não são os únicos, nem os objetivos centrais da alfabetização, porém são necessários para toda aprendizagem acadêmica futura sem os quais ocorreria um atraso na aquisição de conhecimentos na maioria das áreas do currículo ${ }^{16}$.

A disortografia quando não está associada ao quadro de dislexia do desenvolvimento ou distúrbio de aprendizagem é rara, entretanto, muitos escolares apresentam alterações na escrita em decorrência de a escola não enfatizar o ensino da ortografia pela frágil fundamentação teórica e prática de seus educadores ${ }^{17}$. Muitos alunos têm na escola sua principal fonte de contato com a linguagem escrita e, considerando que muitas metodologias atuais de alfabetização não utilizam procedimentos de correção e ensino eficazes da escrita, estas acabam por manter os alunos em situação de desconhecimento da ortografia ${ }^{18-20}$.

Este artigo não visa enfatizar alterações ortográficas decorrentes de problemas no processo de alfabetização por uso de metodologias de ensino que não enfocam a base do princípio alfabético da Língua Portuguesa, e sim a disortografia enquanto manifestação de alteração no processamento fonológico e ortográfico decorrente de condições determinadas genética e neurologicamente, como os transtornos de aprendizagem específico (dislexia do desenvolvimento) e global (distúrbio de aprendizagem).

As características da disortografia fazem parte do processo de apropriação do sistema ortográfico da língua, mas são superadas ao longo da escolarização. No caso de crianças com disortografia decorrente do quadro de transtorno de aprendizagem, essas características não desaparecem com a progressão da escolaridade, mostrando-se persistentes ${ }^{18,19}$.

A caracterização da disortografia se dá pela dificuldade em fixar as formas ortográficas das palavras, apresentando como sintomas típicos a substituição, omissão e inversão de grafemas, alteração na segmentação de palavras, persistência do apoio da oralidade na escrita e dificuldade na produção de textos ${ }^{21}$.

A disortografia é a escrita incorreta, com erros e substituições de grafemas, alteração atribuída às dificuldades no mecanismo de conversão letra-som que interferem nas funções auditivas superiores e nas habilidades linguístico-perceptivas ${ }^{14}$.

A disortografia é parte do quadro da dislexia do desenvolvimento. As crianças que apresentam dislexia do desenvolvimento possuem o sistema fonológico deficiente, ocasionando alterações na conversão letra-som. Assim, a correspondência letra-som não consegue ser armazenada provocando leitura e escrita lenta, confusão entre palavras similares tanto na leitura como na escrita e alteração na compreensão da leitura e escrita ineficiente ${ }^{15,22,23 .}$.

\section{Avaliação e intervenção baseada na semiologia dos erros}

A avaliação e a intervenção na disortografia devem ser centradas na base do sistema de escrita da língua materna. Assim, antes do início da investigação clínica e educacional, professores e terapeutas devem conhecer o sistema de escrita da Língua Portuguesa, ou seja, saber que esse sistema conta com um alfabeto composto de 26 letras, que, isoladas ou combinadas e com os diacríticos, marcas, sinais como acentos gráficos, til e cedilha, representam os fonemas. Assim, enquanto existe uma variedade muito grande de sons, só existem 26 letras para representar a língua portuguesa escrita ${ }^{17}$.

O sistema de escrita do português caracterizase pela Transparência Ortográfica, ou seja, pela regularidade, sendo cada fonema correspondente a um e somente um grafema e vice-versa (cada som corresponde a uma e somente uma letra) e, pela Opacidade Ortográfica, ou seja, pela irregularidade, com grafemas que correspondem a mais de um som e com sons que correspondem a vários grafemas ${ }^{24}$.

A avaliação da ortografia deve trazer informações do nível ortográfico que a criança se encontra, revelando quais são os tipos de erros ortográficos e sua frequência de ocorrência na escrita ${ }^{25}$. De forma geral, deve conter a observação dos próprios trabalhos escolares, ditado sem correção e autocorrigido, escrita de textos longos e curtos, ditado de pseudopalavras ${ }^{14}$, cópia, ditado de letras, escrita de palavras a partir de figuras, ditado de frases e palavras, completar palavras com um ou mais grafemas, completar frases com palavras ${ }^{15}$, tarefa de erro intencional, que fornece informação sobre o nível de conhecimento ortográfico que os escolares possuem ${ }^{24}$ e composição escrita descrevendo pro- 
blemas reais usando conteúdos das diversas disciplinas acadêmicas para a solução dos mesmos ${ }^{26}$.

Subsequentemente, a análise dos dados da avaliação deve ser baseada na observação dos erros que decorrem da alteração do princípio alfabético que afetam a Ortografia Natural e os erros nas convenções ortográficas, independentes deste princípio, que afetam a Ortografia Arbitrária ${ }^{14,15}$.

A classificação baseada na semiologia dos erros ${ }^{14}$ pode ser dividida em dois tipos de erros: os de ortografia natural e de ortografia arbitrária. Os erros de ortografia natural têm uma relação direta com o processamento de linguagem, enquanto que os erros de ortografia arbitrária tanto para a ortografia dependente de regras como a independente de regras estão diretamente relacionados com a memória visual, conhecimento de regras ortográficas, léxico e morfologia. Entre os erros de ortografia natural destacam-se os erros de correspondência fonema-grafema tanto para a correspondência biunívoca como para unívocas dependentes do contexto, que estão diretamente relacionados com o processamento da fala e com a relação letra-som, justificando os erros de substituição grafêmica.

Os erros na sequencialização dos grafemas também estão relacionados com o processamento da fala e se manifestam como erros de omissão e adição de segmentos e alteração na ordem dos segmentos, gerando uma dificuldade para identificar a sequência fonêmica correta durante o processamento da fala e a sua correspondência grafêmica. Outro tipo de erro é o de segmentação da cadeia de fala que ocasionam segmentação indevida de palavras e união incorreta de palavras e estão diretamente relacionados com a consciência lexical.

A figura 1 apresenta as classificações da disortografia segundo a literatura especializada ${ }^{15,27-29}$.

Embora todos esses autores considerem como um tipo de disortografia as situações em que o escritor não se dá conta dos critérios exatos de segmentação ou de separação de uma palavra das outras, pesquisas brasileiras longitudinais sugerem que este comportamento na escrita não está vinculado estritamente a fatos de natureza fonético-fonológica, apontando para um funcionamento normal da escrita infantil, em que poderia ser reduzido a problemas no modo de apropriação de aspectos do código escrito ${ }^{30-32}$.

Em estudo sobre as hipersegmentações, foi verificado que, na alfabetização, o que mais insistentemente está em questão, de um ponto de vista linguístico, é a relação sujeito-língua possibilitada pelo movimento de muitas e complexas práticas de oralidade e de letramento, que entrelaçadas compõem o universo de linguagem do aprendiz da escrita. É a ação dessas práticas sobre o sujeito e/ ou a reflexão que ele faz sobre elas que mais se mostram nas ocorrências de hipersegmentações ${ }^{33}$. É justamente nesse entrelaçamento de práticas que está a busca de critérios do que se pode ou não considerar como palavra já que, em $88,49 \%$ das ocorrências de seu estudo, emergiam justamente palavras sob palavras, e não aleatoriamente cacos de palavras. Em outras palavras, é a história de linguagem do sujeito que se mostra e se mobiliza no processo de alfabetização (e para a qual o alfabetizador deve estar bastante atento).

Em outro estudo desenvolvido foi verificado até que ponto as crianças poderiam ser guiadas por suas intuições sobre constituintes prosódicos da língua ao segmentarem seus textos escritos. Os resultados responderam afirmativamente à questão principal, na medida em que todas as estruturas hipossegmentadas apoiaram-se, de algum modo, em estruturas prosódicas da língua. Destacouse o fato de que o menor número de enunciados fonológicos e o maior número de frases fonológicas parecem indiciar que o conjunto de crianças encaminha-se para a percepção da palavra, tal como estabelecida pelas convenções ortográficas de nossa língua.

Assim, esse autor acredita que não apenas as crianças parecem refletir sobre características da língua que detectam em sua inserção práticas de oralidade, como ainda levam essa reflexão para a atividade de escrita que desenvolvem em suas práticas de letramento ${ }^{34}$.

As estruturas das hipersegmentações frequentemente encontradas na escrita inicial de crianças seriam resultado do trânsito do sujeito escrevente por práticas sociais de oralidade observadas em seu estudo sob a forma de constituintes prosódicos e de letramento, podendo ser vistas como índices do modo heterogêneo de constituição da escrita, sendo assim, marcas de um sistema em construção ${ }^{33,34}$.

Estes estudos levam à reflexão de que a hipersegmentação e a hiposegmentação encontradas na escrita de escolares com dislexia ou distúrbio de aprendizagem não podem ser caracterizadas como próprias destas crianças, uma vez que tanto uma como outra estão presentes e são marcas da construção da escrita de escolares em fase de apropriação do sistema de escrita do português.

A partir da observação e consideração sobre os achados encontrados na avaliação, a intervenção da disortografia deve lançar mão de atividades que se adaptem às características semiológicas de cada tipo de erro e aos fatores cognitivos ou linguísticos implicados, usando uma metodologia que se baseia na aprendizagem direta de palavras e regras ortográficas. O escolar, portanto, aprenderá 


\begin{tabular}{|c|c|c|c|c|}
\hline Cagliari $^{27}$ & Carraher $^{28}$ & Zorzi $^{18}$ & $\begin{array}{l}\text { Cervera - Mérida \& } \\
\text { Ygual Fernández }\end{array}$ & $\begin{array}{c}\text { Manzano, } \\
\text { Sanz \& } \\
\text { Chocano }\end{array}$ \\
\hline $\begin{array}{l}\text { Transcrição } \\
\text { fonética }\end{array}$ & $\begin{array}{l}\text { Transcrição da } \\
\text { fala }\end{array}$ & $\begin{array}{l}\text { Apoio na } \\
\text { oralidade }\end{array}$ & $\begin{array}{c}\text { Erros de ortografia } \\
\text { natural: 1) Erros na } \\
\text { correspondência } \\
\text { biunívoca grafema- } \\
\text { fonema e 2) Erros na } \\
\text { correspondência unívoca } \\
\text { dependente do contexto. }\end{array}$ & $\begin{array}{l}\text { Erros de } \\
\text { caráter } \\
\text { linguístico- } \\
\text { perceptivo }\end{array}$ \\
\hline $\begin{array}{l}\text { Uso indevido de } \\
\text { letras }\end{array}$ & $\begin{array}{l}\text { Erros ligados à } \\
\text { origem das } \\
\text { palavras }\end{array}$ & $\begin{array}{l}\text { Representações } \\
\text { múltiplas }\end{array}$ & $\begin{array}{l}\text { Erros de ortografia } \\
\text { natural: } \\
\text { Erros na sequência dos } \\
\text { grafemas }\end{array}$ & $\begin{array}{c}\text { Erros de } \\
\text { caráter } \\
\text { visoespacial }\end{array}$ \\
\hline Hipercorreção & Supercorreção & $\begin{array}{c}\text { Generalização de } \\
\text { regras }\end{array}$ & $\begin{array}{c}\text { Erros de ortografia } \\
\text { natural: } \\
\text { Erros na Segmentação na } \\
\text { cadeia de fala }\end{array}$ & $\begin{array}{c}\text { Erros de } \\
\text { caráter } \\
\text { visoauditivo }\end{array}$ \\
\hline $\begin{array}{c}\text { Modificação da } \\
\text { estrutura } \\
\text { segmental: trocas, } \\
\text { supressão, } \\
\text { acréscimo e } \\
\text { inversão }\end{array}$ & $\begin{array}{c}\text { Erros nas sílabas } \\
\text { de estruturas } \\
\text { complexas }\end{array}$ & Omissão de letras & $\begin{array}{c}\text { Erros de } \\
\text { ortografia arbitrária: } \\
\text { erros de independentes } \\
\text { de regras e dependente } \\
\text { de regras. }\end{array}$ & $\begin{array}{l}\text { Erros com } \\
\text { relação ao } \\
\text { conteúdo }\end{array}$ \\
\hline $\begin{array}{c}\text { Juntura } \\
\text { intervocabular e } \\
\text { segmentação }\end{array}$ & $\begin{array}{l}\text { Ausência de } \\
\text { segmentação e } \\
\text { segmentação } \\
\text { indevida }\end{array}$ & $\begin{array}{c}\text { Junção/separação } \\
\text { não convencional } \\
\text { de palavras }\end{array}$ & - & $\begin{array}{c}\text { Erros nas } \\
\text { regras } \\
\text { ortográficas }\end{array}$ \\
\hline $\begin{array}{c}\text { Forma morfológica } \\
\text { diferente }\end{array}$ & $\begin{array}{c}\text { Erros por } \\
\text { desconsiderar as } \\
\text { regras } \\
\text { contextuais } \\
\end{array}$ & $\begin{array}{l}\text { Confusão entra } \\
\text { as terminações } \\
\text { am x ão }\end{array}$ & - & - \\
\hline $\begin{array}{l}\text { Forma estranha de } \\
\text { traçar as letras }\end{array}$ & $\begin{array}{c}\text { Erros por } \\
\text { ausência de } \\
\text { nasalização }\end{array}$ & $\begin{array}{l}\text { Trocas surdas / } \\
\text { sonoras }\end{array}$ & - & - \\
\hline $\begin{array}{l}\text { Uso indevido de } \\
\text { maiúsculas e } \\
\text { minúsculas }\end{array}$ & $\begin{array}{c}\text { Erros por trocas } \\
\text { de letras }\end{array}$ & $\begin{array}{l}\text { Acréscimo de } \\
\text { letras }\end{array}$ & - & - \\
\hline Acentos gráficos & - & Letras parecidas & - & - \\
\hline $\begin{array}{l}\text { Sinais de } \\
\text { Pontuação }\end{array}$ & - & Inversão de letras & - & - \\
\hline $\begin{array}{l}\text { Problemas } \\
\text { sintáticos }\end{array}$ & - & Outras trocas & - & - \\
\hline
\end{tabular}

Figura 1 - Classificação das disortografias consoante a literatura

uma grande quantidade de palavras que contém o erro (aprendizagem de competências) com o trabaIho com os déficits nos processos psicolinguísticos subjacentes, mas, desta vez, sem gerar angústia e ansiedade neste ${ }^{14,15,21,34-36}$.

Os aspectos básicos de uma intervenção se iniciam pelo desenvolvimento de algumas noções, tais como: a definição de som e de letra; a explicação de suas relações, estáveis ou convencionais; o nome das letras e as diferenças dos sons que representam e a classificação delas em consoantes e vogais; para poder operar com as regras gramaticais ${ }^{19}$.

Foram propostos para a intervenção da disortografia módulos de trabalho em: metacognição; linguagem oral; consciência fonológica; conhecimento das regras de correspondência fonema-grafema, aplicação das regras de codificação fonemagrafema e automatização do uso das regras na escrita ${ }^{14,37}$ além de uma instrução focada na orto- 
grafia associada à morfologia - estudo da estrutura e formação das palavras e produção textual ${ }^{37-39}$.

Com tudo o que já foi exposto, fica claro que não é a mera exposição dos alunos aos itens escritos e muito menos a tentativa de simples memorização de regras que vai garantir a escrita ortográfica. $A$ ortografia de Línguas com base alfabética possui diversas facetas que devem ser levadas em conta, já que suas regras não são de uma mesma natureza e envolvem diferentes competências para sua aquisição ${ }^{23}$ e anos de prática/exercitação/fixação para seu correto e adequado uso ${ }^{15,40-44}$.

Como parte das estratégias de intervenção e da compreensão da base alfabética do sistema de escrita encontram-se as orientações a pais e professores que os fonoaudiólogos devem realizar. A primeira questão que necessita ser enfocada com pais e professores de crianças com disortografia é que a ortografia é um fim e não um começo. Primeiro, a criança precisa saber lidar com a escrita para depois se preocupar em como escrever ortograficamente, pois ela, na escola, necessariamente deve realizar dois tipos de aprendizados: o princípio do sistema alfabético e a norma ortográfica, ou seja, das restrições regulares e irregulares para a escrita de palavras ${ }^{41}$.

As principais sugestões para orientar pais e professores descritas na literatura ${ }^{19,43,44}$ estão da seguinte forma distribuídas:

a) Sugestões aos professores

- Dizer à criança que você entende a sua dificuldade e que você fará o que for possível para ajudá-la.

- Entender que crianças com disortografia apresentam necessidade de tempo maior para realizar as tarefas escritas e, então, oferecer mais tempo para essa tarefa em sala de aula é necessário.

- Explicar para a criança como a escrita e a ortografia funcionam, podendo, depois, utilizar a produção espontânea da própria criança (palavras e histórias de poucas linhas), para explicar o que ocorreu com a escrita para, em seguida, promover a escrita ortográfica.

- Diferenciar os erros de ortografia das falhas de compreensão e possibilidade de elaboração de respostas, para que a avaliação incida sobre o conteúdo.

- A criança deve saber o que fez e porque precisa corrigir.

- Valorizar o empenho do aluno e não somente o desempenho.

- Ajudar em provas escritas na leitura, para que a criança não fique sem entender.

- Usar provas orais como um recurso extra se a escrita estiver muito comprometida.
- Fazer a correção da ortografia sempre, não permitindo que a criança "fixe" uma forma incorreta de escrita, porém ter critério para a correção dos textos produzidos pelo aluno, sem cometer borrões e rabiscos com canetas coloridas.

- O professor pode assinalar com pequenas marcas os erros ortográficos e solicitar que o aluno procure a grafia correta em um dicionário ou em um fichário de palavras que o grupo de crianças da sala de aula pode montar no decorrer do ano.

b) Sugestões aos pais

- Dizer à sua filha ou ao seu filho que você entende a sua dificuldade e que você estará sempre presente para ajudar.

- Escolher uma escola que seja de sua confiança e aberta para entender suas angústias, dúvidas, frustrações e que possa traçar um plano de trabalho integrado ao processo de intervenção fonoaudiológica.

- Garantir um ambiente sem pressões extremas e exigências demasiadamente altas, que certamente a criança não poderá atingir.

- Ajudar nas tarefas e trabalhos escolares de acordo com a necessidade da criança, com paciência e compreensão, entendendo que ela faz somente o que pode e não porque não quer.

A partir dessas sugestões, os autores citados acreditam que as condições de aprendizagem da criança com disortografia em sala de aula melhoram, o que certamente proporcionará uma qualidade de vida escolar adequada para a continuidade do desenvolvimento da relação ensino-aprendizagem que sempre deve ser desenvolvida em um ambiente educacional acolhedor e estimulante para a criança.

\section{CONCLUSÃO}

Como foi explicitado no decorrer deste artigo, a disortografia é caracterizada como um transtorno da escrita que está diretamente relacionado aos quadros de transtorno específico da aprendizagem, como a dislexia do desenvolvimento e aos transtornos globais da aprendizagem, como o distúrbio de aprendizagem. Por isso, a avaliação fonoaudiológica da ortografia deve trazer informações do nível ortográfico que a criança se encontra, revelando quais são os tipos de erros ortográficos e sua frequência de ocorrência na escrita, isto para que alterações ortográficas decorrentes de problemas no processo de alfabetização não sejam erroneamente classificadas como disortografia.

A partir da classificação semiológica dos erros encontrados na avaliação, a intervenção deve enfatizar atividades que se adaptem às características semiológicas de cada tipo de erro e aos fatores cog- 
nitivos ou linguísticos implicados, associando esses fatores às orientações aos pais e professores de como enfocar o trabalho com a ortografia, seja em casa ou na escola sem gerar angústia e ansiedade na criança.

\section{AGRADECIMENTOS}

À Fundação de Amparo à Pesquisa do Estado de São Paulo - FAPESP pelo auxílio à pesquisa concedido.

\section{ABSTRACT}

Background: evaluation and intervention in dysortographia. Purpose: to describe and discuss findings from researches concerning dysortographia according to its definition, etiology, errors semiology classification, clinical findings, evaluation, and intervention. Conclusion: speech language evaluation and intervention should be based on error semiology classification because in this way it is possible to understand each type of error and the linguistic and cognitive factors related to them. This is associated with the orientations to parents and teachers on how to work with orthography at home or at the classroom without causing distress and anxiety to the children.

KEYWORDS: Evaluation; Rehabilitation; Handwriting; Learning Disorders

\section{REFERÊNCIAS}

1. Capellini SA. Distúrbios de Aprendizagem versus dislexia. In: Ferreira LP, Befi-Lopes DM, Limongi SCO, organizadores. Tratado de fonoaudiologia. São Paulo: Roca; 2004. p. 862-76.

2. Queiroga BAM, Lins MB, Pereira MALV. Conhecimentos morfossintáticos e ortográficos em crianças do ensino fundamental. Psicol Teor Pesq. 2006; 22(1):95-9.

3. Correa J, Maclean M, Meireles ES, Lopes TC, Glockling, D. Using spelling skills in Brazilian Portuguese and English. J Port Linguist. 2007; 6 (1): 61-82.

4. Cunha VLO, Capellini SA. Desempenho de escolares da $1^{\underline{a}}$ a $4^{\underline{a}}$ série do ensino fundamental nas provas de habilidades metafonológicas e de leitura - PROHMELE. Rev Soc Bras Fonoaudiol. 2009; 14(1): 56-68.

5. Cunha VLO, Capellini SA. PROHMELE. Provas de Habilidade Metalinguisticas e de Leitura. Rio de Janeiro (RJ): Revinter; 2009.

6. Savage RS, Frederickson N, Goodwin R, Patni $\mathrm{U}$, Smith N, Tuerley L. Relationships among rapid digit naming, phonological processing, motor automaticity, and speech perception in poor, average, and good readers and spellers. J Learn Disabil. 2005; 38(1):12-28.

7. Puolanaho A, Ahonen T, Miko A, Eklund $\mathrm{K}$, Lepänen PHT, Poikkeus AM, et al. Very early phonological and language skills: estimating individual risk of reading disability. J Child Psychol Psychiatr. 2007; 48(9):923-31.
8. Godoy DMA. O papel da consciência fonológica no processo de alfabetização. Pró-Fono. 2003; 15(3):241-50.

9. Cárnio MS, Stivanin L, Vieira MP, Amaro L, Martins VO, Carvalho EE, et al. Habilidades de consciência fonológica e letramento em crianças do ensino fundamental. Rev Soc Bras Fonoaudiol. 2006; 11(4):231-42.

10. Gindri G, Keske-Soares M, Mota HB. Memória de trabalho, consciência fonológica e hipótese de escrita. Pró-Fono. 2007; 19(3):313-22.

11. Bitan T, Cheon J, Lu D, Burman DD, Booth JR. The interaction between orthographic and phonological information in children: an $\mathrm{fmRl}$ study. Hum Brain Mapp. 2007; 28 (9): 880-91.

12. Serrano F, Defior S. Dyslexia speed problems in a transparent orthography. Ann Dyslexia. 2008; 58(1):81-95.

13. Associação Psiquiátrica Americana. Manual diagnóstico e estatístico de transtornos mentais. Porto Alegre (RS): Artes Médicas; 2000.

14. Cervéra-Mérida JF, Ygual-Fernández AA. Uma propuesta de intervención em trastornos disortográficos atendiendo a la semiologia de los errores. Rev Neurol. 2006; 42(2):117-26.

15. Manzano JLG, Sanz MT, Chocano AJD. Fundamentos para la intervención en el aprendizaje de la ortografia. Madrid, Espanha: Editorial CEPE; 2008. p.13-234.

16. Scliar-Cabral L. Princípios do sistema alfabético do português do Brasil. São Paulo: Contexto; 2003. 
17. Berberian AP, Massi GA. A clínica fonoaudiológica voltada aos chamados distúrbios de leitura e escrita: uma abordagem constitutiva da linguagem. Rev Soc Bras Fonoaudiol. 2005; 10(1):43-52.

18. Zorzi L. Aprender a escrever: a apropriação do sistema ortográfico. Porto Alegre: Artes Médicas; 1998.

19. Zorzi JL. Guia prático para ajudar crianças com dificuldades de aprendizagem: dislexias e outros distúrbios. Pinhais: Melo; 2008.

20. Graham S, Perin, D. What we know, what we still need to know: teaching adolescents to write. Scient Stud Read. 2007; 11: 313-335.

21. Galaburda AM, Cestinick L. Dislexia del desarollo. Rev Neurol. 2003; 36(1):13-23.

22. Boets B, Wouters J, Van Wieringen A, De Smedt $B$, Ghesquiére $P$. Modelling relations between sensory processing, speech perception, orthographic and phonological ability, and literacy achievement. Brain Lang. 2008; 6(1):29-40.

23. Capellini SA, Ávila CRB. Relation between oral and written language. In: Capellini SA, organizador. Neuropsycholinguistic perspectives on dyslexia and other learning disabilities. New York: Nova Science Publishers; 2007. p. 15-21.

24. Meirelles E, Correa J. A relação da tarefa de erro intencional com o desempenho ortográfico da criança considerados os aspectos morfossintáticos e contextuais da língua portuguesa. Estud. Psicol. 2006; 11(1):35-43.

25. Zorzi JL, Ciasca SM. Caracterização dos erros ortográficos em crianças com transtornos de aprendizagem. Rev. CEFAC. 2008; 10(3):321-31.

26. KuliKowich JM, Mason LH, Brown SW. Evaluating fifth- and sixth-grade students' expository writing: task development, scoring, and psychometric issues. Read Writ. 2008; 21:153-75.

27. Cagliari LC. Breve histórias das letras e dos números. In: CAGLIARI, L. C. Diante das letras. A escrita na alfabetização. Campinas, SP: Mercado das Letras: Associação de Leitura do Brasil - ALB; São Paulo: Fapesp; 1999.

28. Carraher TN. Explorações sobre o desenvolvimento da ortografia em português. In: Isto se aprende com o ciclo básico. São Paulo. Secretaria de Estado da Educação - CENP; 1990. p.114-22.

29. Cervera-Mérida JF, Ygual- Fernandez A. La intervención logopédica en los trastornos fonológicos desde El paradigma psicolingüístico Del procesamiento de habla. Rev Neurol. 2003; 36 (Supl 1): S39-53.

30. Chacon L. Constituintes prosódicos e letramento em segmentações não-convencionais. In: Chacon L. O modo heterogêneo de constituição da escrita: um olhar sobre a escrita infantil. In: Lamprecht R, organizador. Letras Hoje. 2004; 39(3):223-31.

31. Tenani L. Segmentações não-convencionais e teorias fonológicas. In: Chacon L. O modo heterogêneo de constituição da escrita: um olhar sobre a escrita infantil. In: Lamprecht $\mathrm{R}$, organizador. Letras Hoje. 2004; 39(3):p. 233-43.

32. Capristano CC. A propósito da escrita infantil: uma reflexão sobre as segmentações nãoconvencionais. In: Chacon L. O modo heterogêneo de constituição da escrita: um olhar sobre a escrita infantil. Letras Hoje. 2004; 39(3):245-60.

33. Chacon L. Hipersegmentações na escrita infantil: entrelaçamentos de práticas de oralidade e de letramento. Estud Ling. XXXIV. 2005; 83(86):77-86.

34. Chacon L. Segmentações não-convencionais na escrita de pré-escolares: entrecruzamentos entre convenções ortográficas e constituintes prosódicos. In: Lamprecht $\mathrm{R}$, organizador. Aquisição da linguagem: estudos recentes no Brasil. Porto Alegre: Editora da PUCRS; 2009. p. 282-5 (no prelo).

35. Salles JS, Parente MAMP. Avaliação da leitura e escrita de palavras em crianças de $2^{\text {a }}$ série: abordagem neuropsicológica cognitiva. Psicol Reflex Crit. 2007; 20(2):220-8.

36. Zorzi JL, Ciasca SM. Análise de erros ortográficos em diferentes problemas de aprendizagem. Rev. CEFAC. 2009; 11(3):406-16.

37. Pérez-Blasco J, Ferri-Benedetti $F$, Melià-De Alba A, Miranda-Casas A. Resiliencia y riesgo em niños com dificultades de aprendizaje. Rev Neurol. 2007; 44 (Supl 2): S9-12.

38. Berninger VW, Winn WD, Stock P, Abbott RD, Kate Eschen K, Lin S, et al. Tier 3 specialized writing instruction for students with dyslexia. Read Writ. 2008; 21:95-129.

39. Mason LH, Graham S. Writing instruction for adolescents whith learning disabilities: programs of intervention research. Learn Disabil Res Pract. 2008; 23(2): 103-11.

40. Walker B, Shippen ME, Alberto P, Houchins DE, David F, Cihak, DF. Using the expressive writing program to improve the writing skills of high school students whith learning disabilities. Learn Disabil Res Pract. 2005; 20(3): 175-83.

41. Troia G, Graham S. The effectiveness of a highly explicit, teacher-directed strategy instruction routine: changing the writing performance of participants with learning disabilities. J Learn Disabil. 2002; 35: 290-305.

42. Ritchey KD. Learning to write: progressmonitoring tools for beginning and at-risk writers. Teach Exc child. 2006; 39(2): 22-6. 
43. Capellini AS, Cunha VLO, Batista AO. Disortografia: avaliação e intervenção baseada na semiologia do erro. In: Montiel JM, Capovilla FC, organizadores. Atualização em transtornos de aprendizagem. São Paulo: Artes Médicas; 2009. p.567-84.
44. Capellini AS, Conrado TLBC, Tegeiro MG, Cera ML, Gonçalves MPS, Ferreira ALB. Dificuldades de aprendizagem: manual de orientação para professores e informativo para familiares. Marília: Fundepe Editora; 2007.

RECEBIDO EM: 10/12/2009

ACEITO EM: 05/02/2010

Endereço para correspondência:

Simone Aparecida Capellini

Rua Bartolomeu de Gusmão, 10-84

Bauru - SP

CEP: $17017-336$

E-mail: sacap@uol.com.br amparo.ygual@uv.es 